\title{
Lymphocyte population and apoptosis in the lungs of smokers and their relation to emphysema
}

\author{
J. Majo*, H. Ghezzo\#, M.G. Cosio"
}

Lymphocyte population and apoptosis in the lungs of smokers and their relation to emphysema. J. Majo, H. Ghezzo, M.G. Cosio. C) ERS Journals Ltd 2001.

ABSTRACT: Previously, it had been shown that T-lymphocytes are the predominant inflammatory cells found in the alveolar wall of smokers and their numbers correlated with the extent of emphysema. However, the phenotype of these cells was not defined. The aim of this study was to describe the different $T$-cell phenotypes and investigate the possible presence of apoptosis in the lung parenchyma of smokers.

Samples from lungs were obtained at surgery from 15 patients who smoked and six who had never smoked. Samples were frozen and prepared for histological and immunocytochemical examination. Slides were stained for $\mathrm{CD3}+, \mathrm{CD} 4+, \mathrm{CD8}+, \gamma \delta$ T-cells, CD56 natural killers ((NK) cells), and elastase (neutrophils). Anti-CD95 monoclonal antibodies and in situ end-labelling techniques were used to detect Fas expression and apoptosis. Positive staining cells were expressed as cells $\cdot \mathbf{m m}$ alveolar wall $^{-1}$, percentage of total cells, and Fas/APO and apoptosis index. Emphysema was identified macroscopically, microscopically and reported as present or absent. All subjects had pulmonary function tests before surgery.

Neutrophils were the predominant cell in the lung parenchyma of nonsmokers and smokers without emphysema. In smokers with emphysema, the CD3 + and CD8 + were the predominant cells $(p<0.05)$ in the alveolar wall. $\gamma \delta$ cells were increased in all smokers and no increased numbers of NK cells was found. The T-cell numbers $\cdot \mathbf{m m}$ alveolar wall ${ }^{-1}$ showed a bilinear relationship with the amount smoked increasing at an inflection point of 30 packs $\mathrm{yr}^{-1}\left(\mathrm{R}^{2}=0.345 ; \mathrm{p}<0.01\right)$. Apoptosis in smokers showed a bilinear relationship with the amount smoked increasing sharply in smokers with emphysema $\left(R^{2}=0.3613 ; p<0.009\right)$.

It is concluded that the pathogenesis of emphysema might be mediated by T-lymphocytes, mainly CD8 + cytolytic T-cells, and that apoptosis might be one of the mechanisms of lung destruction leading to the development of emphysema. If this is the case, it could be speculated that $T$-cell inflammation is a response to antigenic stimuli originating in the lung and induced by cigarette smoking.

Eur Respir J 2001; 17: 946-953.
*Dept d'Anatomia Patologica, Hospitals Universitaris Vall d'Hebron, Barcelona, Spain, ${ }^{\#}$ Meakins Christie Laboratories, Montreal, Quebec, Canada and "MUHC Respiratory Division, Royal Victoria Hospital \& Meakins Christie Laboratories, Montreal, Quebec, Canada.

Correspondence: M.G. Cosio, McGill University, Respiratory Division, Royal Victoria Hospital, 687 Pine Avenue West, Montreal, Quebec, Canada, H3A 1A1 Fax: 15148431695

\section{Keywords: Apoptosis}

$\mathrm{CD} 8+$

chronic obstructive pulmonary disease emphysema

T-cells

T-lymphocytes

Received: July 32000

Accepted after revision December 12 2000

Supported in part by the Costello J.T Memorial Fund and the Medical Research Council of Canada Center of Excellence "Inspiraplex". J. Majo was funded by the Barcelona-Quebec Exchange Fellowship and the Canadian Lung Association Fellowship.
A smoking induced inflammatory reaction in the airways and lung parenchyma, comprised of neutrophils and alveolar macrophages [1-4], has long been accepted to be the major cause of the development of airway abnormalities and emphysema and, consequently, chronic obstructive pulmonary disease (COPD) in susceptible smokers. This concept is derived from findings of increased numbers of macrophages and neutrophils in bronchoalveolar lavage [4-6], a compartment that might or might not reflect events in the lung parenchyma.

Few studies have attempted to directly describe the inflammation of the alveolar walls of smokers, the site of lung destruction in COPD, since ANDERSON and FORAKER [7] observed that one of the earliest changes in emphysema was hypercellularity of the alveolar wall. EIDELMAN et al. [8] quantitated this hypercellularity and found a direct correlation between the extent of emphysema and number of cells in the alveolar wall of smokers, but an inverse relationship between emphysema and numbers of neutrophils, a finding that suggested that other inflammatory cells might be involved in the pathogenesis of emphysema. Following these findings, FinKelstein et al. [9] reported that principally the number of T-lymphocytes $(\mathrm{CD} 3+)$, and also the alveolar macrophages increased in alveolar walls of smokers lungs and that their number correlated directly with the extent of emphysema. However, the phenotype of these lymphocytes was not defined.

More recent studies, quantitating the inflammation of the airways in smokers and defining their phenotype, found that the predominant inflammatory cell present was the $\mathrm{CD} 8+\mathrm{T}$-cell and that their number correlated inversely with the degree of airflow limitation [10-12]. These findings are suggestive of the possible role of CD8 $+\mathrm{T}$-cells in the pathogenesis of airway abnormalities in COPD. It was speculated that 
the CD $8+$ T-lymphocyte would also be the predominant T-cell found in the lung parenchyma of smokers with emphysema.

This study was undertaken to define the phenotypes of T-cells in the lung parenchyma of smokers, as such information was not available. Because one of the important effects on functions of T-cells, especially $\mathrm{CD} 8+$, is cytolytic, inducing cell death by perforin mediated lysis and apoptosis either by caspase activation or Fas-FasL ligand engagement, the presence of Fas expressing and apoptotic cells in the lung was also investigated as indirect evidence of $\mathrm{T}$-cell mediated cytotoxicity.

\section{Methods}

Twenty-one patients undergoing thoracotomy for a localized nonobstructing peripheral lung mass were studied. Fifteen were smokers and six had never smoked. None had a history of asthma or occupational exposure to dust.

Pulmonary function tests were performed before surgery according to National Institutes of Health standard protocol [13]. Spirometry was performed on an MGC 1070 PFT (Medical Graphics Corporation, St. Paul, MN, USA), module and lung volumes were measured in a body plethysmograph. All values were expressed as per cent predicted, based on the prediction formulas of MoRris et al. [14] and GOLDMAN and BECKLAKE [15].

Lungs were obtained directly from the operating room. Three to five tissue wedges, $\sim 4 \times 4 \times 1 \mathrm{~cm}$, selected in a random manner, were cut from each lung at least $5 \mathrm{~cm}$ away from the tumour and distended with cryoembedding material (OCT tissue Tek R. Miles Laboratories Inc., Miles Scientific Division, Naperville, IL, USA) using a syringe and needle, frozen in liquid nitrogen and kept at $-80^{\circ} \mathrm{C}$ until use. Surgical specimens (whole lung or lobe) were inspected macroscopically and lung biopsies microscopically for the presence of emphysema and the cases were classified as having, or not having, emphysema according to published guidelines [16].

From each block, 20 5-micron thick sections were cut at $-20^{\circ} \mathrm{C}$ and fixed in $10 \%$ formalin for $7 \mathrm{~min}$. One section was stained with haematoxylin-eosin, and the remaining 19 sections were prepared for immunocytochemistry using the alkaline phosphatase- anti-alkaline phosphatase-method [17] and counter stained with Mayers haematoxylin for $1 \mathrm{~min}$. The following primary antibodies (Dako Corporation, Carpenteria, CA, USA) were used: CD3 (T-lymphocytes), CD4 (helper T-lymphocytes) CD8 (cytotoxic T-lymphocytes), $\gamma \delta$ T-lymphocytes, CD56 (Natural killer (NK) cell), and elastase (Neutrophils). The antibody antigen reaction was developed with the alkaline phosphataseanti-alkaline phosphatase-complex and Fast Red (Sigma Chemical Co., St. Louis, MO, USA), resulting in bright red colour. Reactive lymph nodes or spleen samples were used for positive controls.

Two nonconsecutive slides per block for each antibody were quantified in two ways, and results expressed as the mean of the two slides. In 28 randomly selected fields (17-39) a minimum of 1,000 nucleus slide were counted, and positive staining cells were expressed as percentage of total cells. Consequently on the same field, the length of the alveolar wall was digitized (Panasonic Digital 5100 camera; Matsushita Communications Industrial Co. Ltd, Japan, and Leitz Dialux 20 microscope; Leitz Weslar, Germany) and the number of cells and positive staining cells in, or in close contact with, the alveolar wall counted. A minimum of $10 \mathrm{~mm}$ of alveolar wall per slide were studied (average: $21.35 \pm 5.37 \mathrm{~mm} \cdot \mathrm{slide}^{-1}$ ). Cells were expressed as number $\cdot \mathrm{mm}$ of alveolar wall ${ }^{-1}$.

Fas/APO-1 expression, and the detection of intranucleosomal deoxyribonucleic acid fragmentation by the in situ end-labelling technique (ISEL) were used to quantify Fas expressing cells and cells undergoing apoptosis in the alveolar walls, respectively. Cells expressing Fas/APO-1 were detected using anti-CD95 monoclonal antibody (Novocasta Lab Ltd, Newcastle Upon Tyne, UK) and a Dako-labelled streptavidinbiotin staining kit (Dako Corporation). Briefly, two slides per block were incubated in peroxidase blocking solution, then antibody anti-CD95 (Fas/APO-1) was applied. After incubation and application of biotinlayed anti-immunoglobulins and streptavidin horse radish peroxidase, the slide was developed with 3-Amino-9-ethylcarbazole (AEC) (Sigma Chemical Co., St Louis, MO, USA) obtaining a bright orangebrown colour. Frozen lymph nodes for positive controls were used. Cell apoptosis in tissue sections was studied with the in situ apoptosis detection kit-

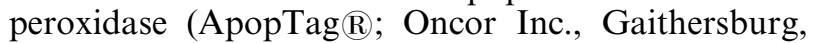
MD, USA) following the manufacturer's protocol using the ISEL technique. Briefly, 5-mm thick sections from the frozen blocks were cut, fixed in $10 \%$ formalin for $7 \mathrm{~min}$ and after dipping the slides in ethanol acetic acid $2: 1$ for $5 \mathrm{~min}$ at $-20^{\circ} \mathrm{C}$, the endogenous peroxidase activity was quenched with $1 \%$ hydrogen peroxide in methanol for $20 \mathrm{~min}$. Subsequent endlabelling with Digoxigenin mixed with terminal deoxynucleotidyl transferase (TdT) enzyme in a 2:1 ratio was carried out in a humidified chamber at $37^{\circ} \mathrm{C}$ for $1 \mathrm{~h}$ and after washing with phosphate buffered saline (PBS) anti-digoxigenin, peroxidase was applied and incubated in a humidified chamber at room temperature for $30 \mathrm{~min}$. Slides were rinsed with PBS and then 3,3'-diamenobenzadine (DAB) (Aldrich Chemical Co., Milwaukee, WI, USA) was applied for $6 \mathrm{~min}$ as a chromogenic substrate. A brown-black stain appeared in the site of reaction (fig. 1). Two consecutive sections for each block were stained, quantitated and the mean of the two slides was reported. Rat testes or thymuses were used for positive controls.

Because very few cells expressed Fas or apoptosis, these parameters were not expressed as cells $\cdot \mathrm{mm}$ alveola wall $^{-1}$; instead all the cells staining positive with Fas/APO-1 and ApopTag $\mathbb{R}$ in each slide were quantitated. The number of cells in each slide were divided by the digitized slide area and multiplied by the slide mean linear intercept (Lm) [18], as a correction for the different amount of pulmonary parenchyma in each particular slide. This calculation 


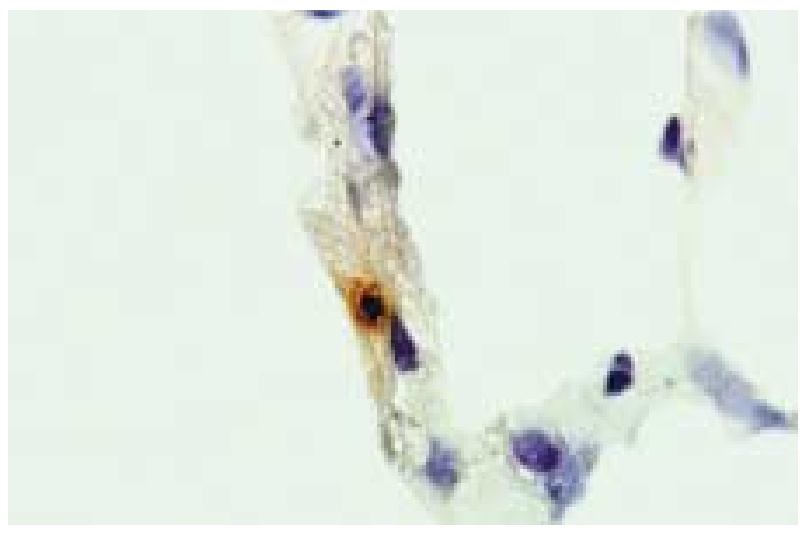

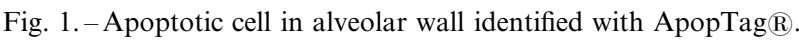
Magnification $\times 1,000$.

was expressed as the Fas and apoptosis indexes.

$$
\text { Index }=\frac{\text { Number }(+) \text { ve cells }}{\text { Area }\left(\mathrm{cm}^{2}\right)} \times \mathrm{Lm}
$$

After cell quantitation, the code was revealed and patients were then separated by smoking history, and presence or absence of emphysema into three groups: 1) nonsmokers without emphysema (six patients); 2) smokers without emphysema (five patients); and 3) smokers with anatomical emphysema (10 patients) who had mild-to-moderate airflow obstruction and hyperinflation.

\section{Data analysis}

The data were analysed with a nonparametric statistical package. Group data are expressed as mean \pm SD. The two-tail Wilcoxon test was used for comparison of means. For the three groups comparison the Kruskal-Wallis test was used. The exploratory data analysis (EDA) was performed using the Lowess (locally weighted smoothing scatter plots) smoothing method when appropriate [19]. The Lowess is an EDA method that can be utilized to fit a locally best nonparametric line to the data being analysed. The curve (or line) thus fitted can suggest a mathematical model (parabolic, bilinear, exponential, etc.) which then can be tested versus a general linear equation. Data analysis was performed with S-plus (4.5 version) computer program (Math Soft, Seattle, Washington, USA). The 5\% level of confidence for statistical significance was accepted.

\section{Results}

Mean values for age, smoking history and pulmonary function tests are shown in table 1 . Six patients had never smoked and had no emphysema. Of the smokers, 10 had emphysema and five had no emphysema (macroscopically or microscopically). The age was similar in all groups. The forced expiratory volume in one second (FEV1) \% pred was lower in smokers with emphysema than in nonsmokers and
Table 1.-Patient characteristics

Non-smokers Smokers without Smokers with emphysema emphysema

\begin{tabular}{lccc}
\hline Subjects n & 6 & 5 & 10 \\
Age yr & $65 \pm 9$ & $67 \pm 10$ & $65 \pm 8$ \\
Sex M/F & $1 / 5$ & $3 / 2$ & $9 / 1$ \\
Pack-yrs & & $29 \pm 14$ & $47 \pm 15$ \\
FEV \% pred & $99.2 \pm 15.1$ & $98.9 \pm 17.7$ & $77.6 \pm 21.9$ \\
FRC \% pred & $94.8 \pm 15.9$ & $108.6 \pm 26.7$ & $122.7 \pm 25.2$ \\
\hline
\end{tabular}

Data presented as mean $+\mathrm{SD}$; M: male; F: female; FEV1: forced expiratory volume in one second; FRC: functional residual capacity.

smokers without emphysema $(p<0.05)$. The functional residual capacity $\%$ pred was higher in smokers with emphysema than nonsmokers and smokers without emphysema $(\mathrm{p}<0.05)$.

Table 2 shows the morphometric results in nonsmokers and in smokers with and without emphysema. The total number of cells per millimetre of alveolar wall was similar in all groups. The inflammatory profile in nonsmokers and smokers, divided according to absence or presence of emphysema, is shown in figure 2 . Nonsmokers had more neutrophils than lymphocytes and CD4 + T-cells were more numerous than CD8 + T-cells. The profile of the smokers without emphysema was similar to the nonsmokers. Smokers with emphysema had a different profile with a significant increase in CD3 + and $\mathrm{CD} 8+$ cells $\cdot \mathrm{mm}$ alveolar wall ${ }^{-1}(\mathrm{p}<0.05)$. The percentells (NK) was similar in all groups.

Fas/APO-1 was expressed in less than half of the lungs studied and there were no differences among groups. Apoptosis was present in all lungs studied, and the apoptotic index was similar in all groups (table 2).

Figure 3 shows the correlation between packs $\cdot \mathrm{yr}^{-1}$ smoked and CD3 + cells $\cdot m m$ alveolar wall ${ }^{-1}$. The correlation is best described with the Lowess smoothing technique as a bilinear relationship with an inflection point at 30 packs $\mathrm{yr}^{-1}\left(\mathrm{R}^{2}=0.345 ; \mathrm{p}=0.01\right)$, after which CD3 + T-cell numbers increased and emphysema was evident. Figure 4 shows that the same model applies to $\mathrm{CD} 8+\left(\mathrm{R}^{2}=272 ; \mathrm{p}=0.03\right)$, and $\mathrm{CD} 4+$ $\left(\mathrm{R}^{2}=0.220 ; \mathrm{p}=0.051\right)$. There was no correlation between CD56+ T-cells (NK), $\gamma \delta$ T-cells or the elastase + cells $\cdot \mathrm{mm}$ alveolar wall ${ }^{-1}$ and packs $\cdot \mathrm{yr}^{-1}$.

Figure 5 shows that in nonsmokers, there was a significant correlation $(r=0.829 ; p<0.05)$ between the total number of cells $\cdot \mathrm{mm}$ alveolar wall ${ }^{-1}$ (structural and inflammatory) and the apoptotic index. In smokers, no such relationship was found $(r=-0.29$; $\mathrm{p}=\mathrm{NS}$ ), probably indicating that different cell types undergo apoptosis in nonsmokers than in smokers. Figure 6 shows the relationship between the apoptosis index and the dose of smoking (packs $\left.\cdot \mathrm{yr}^{-1}\right)$. The apoptosis index in smokers without emphysema decreased from the mean apoptosis index in nonsmokers to a minimum of $\sim 40$ packs $\cdot \mathrm{yr}^{-1}$, and then increased significantly, as the packs $\mathrm{yr}^{-1}$ increased in the smokers with emphysema. This is best described 
Table 2. - Morphometric results

\begin{tabular}{|c|c|c|c|}
\hline & Non-smokers & Smokers without emphysema & Smokers with emphysema \\
\hline Subjects $n$ & 6 & 5 & 10 \\
\hline Total cells. $\mathrm{mm}^{-1}$ & $42.53 \pm 6.21$ & $47.02 \pm 6.46$ & $46.66 \pm 6.75$ \\
\hline Elastase + cells. $\mathrm{mm}^{-1}$ & $2.24 \pm 1.24$ & $1.61 \pm 0.85$ & $1.40 \pm 0.73$ \\
\hline $\mathrm{CD} 3+$ cells. $\mathrm{mm}^{-1}$ & $0.95 \pm 0.65$ & $0.75 \pm 0.27$ & $1.81 \pm 1.07$ \\
\hline $\mathrm{CD} 4+$ cells. $\mathrm{mm}^{-1}$ & $0.41 \pm 0.30$ & $0.25 \pm 0.16$ & $0.71 \pm 0.56$ \\
\hline $\mathrm{CD} 8+$ cells.mm $\mathrm{m}^{-1}$ & $0.20 \pm 0.07$ & $0.26 \pm 0.21$ & $0.63 \pm 0.38$ \\
\hline Ratio CD4/CD8 (cells.mm¹) & $2.36 \pm 2.06$ & $2.53 \pm 3.57$ & $1.26 \pm 0.73$ \\
\hline$\gamma \delta+$ cells. $\mathrm{mm}^{-1}$ & $0.01 \pm 0.01$ & $0.03 \pm 0.03$ & $0.03 \pm 0.03$ \\
\hline CD56+ cells. $\mathrm{mm}^{-1}$ & $0.01 \pm 0.01$ & $0.02 \pm 0.03$ & $0.02 \pm 0.02$ \\
\hline$\%$ Elastase + cells & $5.09 \pm 2.44$ & $3.51 \pm 1.91$ & $3.08 \pm 1.75$ \\
\hline$\%$ CD3 + cells & $2.13 \pm 1.12$ & $1.67 \pm 0.61$ & $3.84 \pm 1.93$ \\
\hline$\%$ CD $4+$ cells & $1.02 \pm 0.73$ & $0.53 \pm 0.34$ & $1.51 \pm 1.03$ \\
\hline$\%$ CD $8+$ cells $^{\#}$ & $0.5+0.17$ & $0.54+0.35$ & $1.53+0.96$ \\
\hline Ratio CD4/CD $8 \%$ cells & $3.23 \pm 2.63$ & $2.19 \pm 2.85$ & $1.26 \pm 0.81$ \\
\hline$\% \gamma \delta+$ cells $^{\#}$ & $0.02 \pm 0.03$ & $0.08 \pm 0.08$ & $0.08 \pm 0.07$ \\
\hline$\%$ CD $56+$ cells & $0.03 \pm 0.05$ & $0.04 \pm 0.06$ & $0.04 \pm 0.05$ \\
\hline FAS Index & $0.14 \pm 0.22$ & $0.03 \pm 0.06$ & $0.24 \pm 0.27$ \\
\hline Apoptotic Index & $1.96 \pm 1.40$ & $1.31 \pm 0.85$ & $1.20 \pm 1.13$ \\
\hline
\end{tabular}

Results are presented in mean \pm SD. ${ }^{*}: \mathrm{p}<0.05$, Kruskal-Wallis.

by the Lowess technique as a bilinear relationship with an inflection point at 40 packs $\cdot \mathrm{yr}^{-1}\left(\mathrm{R}^{2}=0.3613\right.$; $\mathrm{p}=0.009)$. The number of CD $8+\mathrm{T}$-cells and apoptosis index in all smokers with emphysema correlated with an $r=0.324$ (NS). When an exsmoker with emphysema was removed, the correlation between numbers of $\mathrm{CD} 8+$ and apoptic index became significant with an $\mathrm{r}=0.642 ; \mathrm{p}<0.05$.

The Fas Index did not correlate with the total number of cells or inflammatory cells in nonsmokers. In smokers (with and without emphysema), the Fas index was correlated with the number of $\mathrm{CD} 3+$ $\mathrm{T}$-cells $\cdot \mathrm{mm}$ per alveolar wall ${ }^{-1}(\mathrm{r}=0.675 ; \mathrm{p}<0.006)$ and $\mathrm{CD} 4+\mathrm{T}$-cells per alveolar wall $(\mathrm{r}=0.564$; $\mathrm{p}<0.020$ ) but not with the number of $\mathrm{CD} 8+$ T-cells $\cdot \mathrm{mm}$ per alveolar wall ${ }^{-1}(\mathrm{r}=0.396 ; \mathrm{p}=\mathrm{NS})$. The Fas index was not correlated with the amount smoked $\left(\right.$ packs $\left.\cdot \mathrm{yr}^{-1}\right)$.

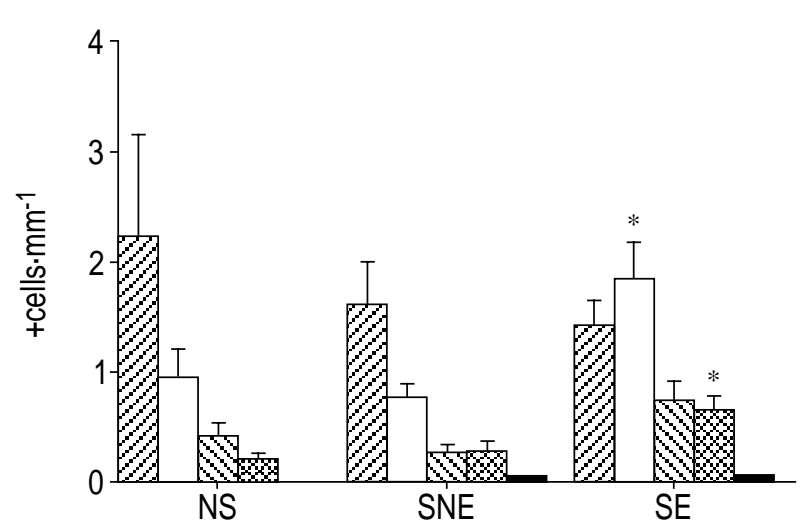

Fig. 2. - Inflammatory cell profile in the lungs of nonsmokers (NS), smokers without anatomical emphysema (SNE) and smokers with emphysema (SE). Cells are expressed as a mean $\pm S E M$ number of cells $\cdot \mathrm{mm}$ alveolar wall ${ }^{-1}$. $\mathbb{Z}$ : Elastase; $\square$ : CD3; $\mathbb{\mathbb { N }}$ : CD4; 网: CD8; $\square: \delta \alpha ; *: p<0.05$.

\section{Discussion}

Since FinKelstein et al. [9] described the presence of T-cells in smokers' lungs, the associations between smoking, COPD, FEV1 and T-lymphocyte infiltration in the lower respiratory tract of smokers have been described [10-12, 20-22], suggesting that T-lymphocytes play a role in the pathogenesis of COPD. Furthermore, the extent of emphysema in smokers is related to the number of CD3 + T-cells in the alveolar wall [9], a finding that seems to implicate the T-lymphocyte in the pathogenesis of emphysema. In the present work, the authors wanted to define further the phenotype of the T-cells in the alveolar wall, as this would provide information about which, and how, T-cells might be involved in the mechanism of lung destruction. It was found that all T-lymphocyte phenotypes were increased in smokers with emphysema,

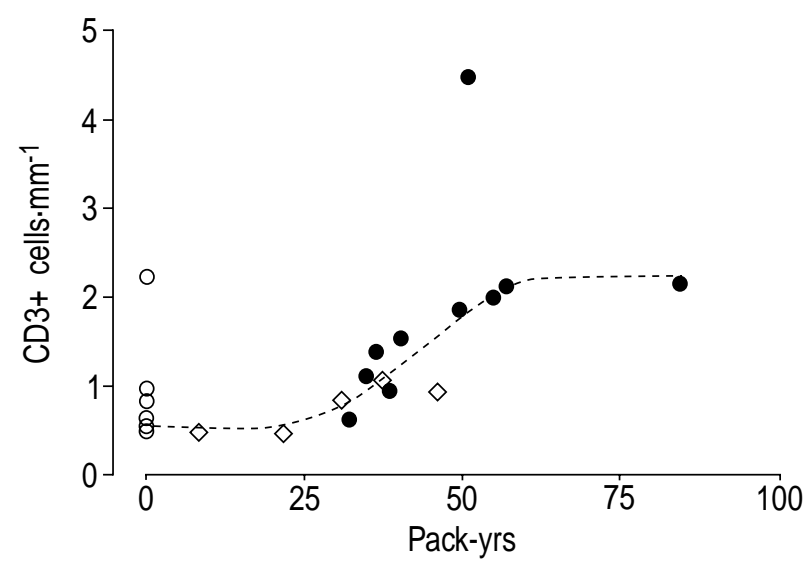

Fig. 3.-Relationship between the amount smoked (pack-yrs) and the number CD3 + T-cells per mm of alveolar wall. $\bigcirc$ : nonsmokers; $\diamond$ : smokers with no emphysema; $\bigcirc$ : smokers with emphysema. --- : Lowess smoothing fit defining a bilinear relationship with $\mathrm{R}^{2}=0.3451, \mathrm{p}=0.01$ 

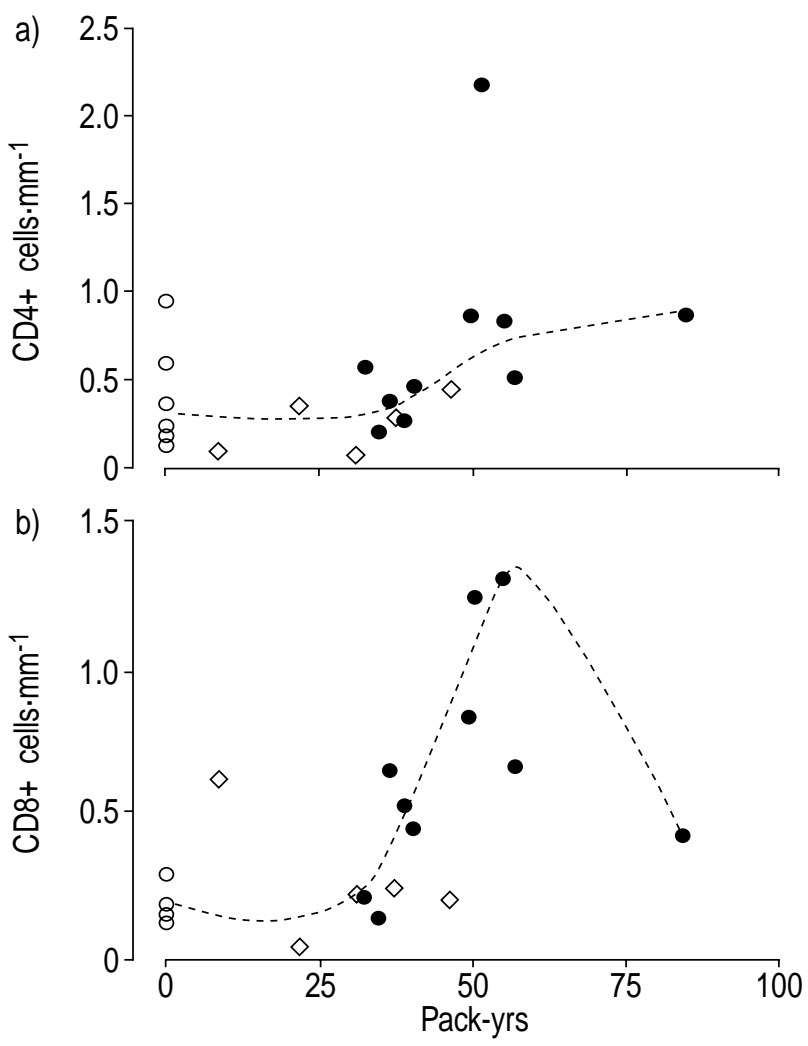

Fig. 4. - Relationship between pack-yrs of smoking and CD4+ and CD8 + T-cells per mm of alveolar wall. $\bigcirc$ : nonsmokers; $\diamond$ : smokers with no emphysema; $\bullet$ : smokers with emphysema. --- : Lowess smoothing fit and defining a bilinear relationship for $\mathrm{CD} 4+: \mathrm{R}^{2}=0.2191, \mathrm{p}=0.05$ and $\mathrm{CD} 8+: \mathrm{R}^{2}=0.2718, \mathrm{p}=0.03$. (The point at 89 pack-yrs seen as an outlayer in the CD8+ graph belonged to an exsmoker).

with a predominance of the $\mathrm{CD} 8+\mathrm{T}$-cell, and that this increase followed a biphasic relationship with the smoking dose. It was also found that apoptosis in active smokers with emphysema increased together with the amount smoked and the number of CD8+ T-cells after a certain dose of smoking was reached (40 packs $\left.\cdot \mathrm{yr}^{-1}\right)$ suggesting that cytotoxicity may play a part in the pathogenesis of emphysema.

Lung biopsies were distended as much as possible with cryoembedding material (OCT) injection allowing for a good picture of the lung structure but not for precise morphometry. Therefore, the presence of emphysema was identified by careful microscopic and macroscopic examination of the lung and microscopic sections, and expressed as present or absent [16]. Alveolar length was measured, a magnitude less affected by differences in distending lung pressures, to express the number of cells per $\mathrm{mm}$ in the alveolar wall [8]. The percentages of inflammatory cells, as a proportion of the total cells in the alveolar wall, showed similar results, promoting confidence in the morphometric findings.

The separation of the population into nonsmokers and smokers, with and without emphysema, showed that nonsmokers' lungs were infiltrated mainly by variable numbers of neutrophils and T-cells of which CD4 + T-cells outnumbered CD + cells. Smokers
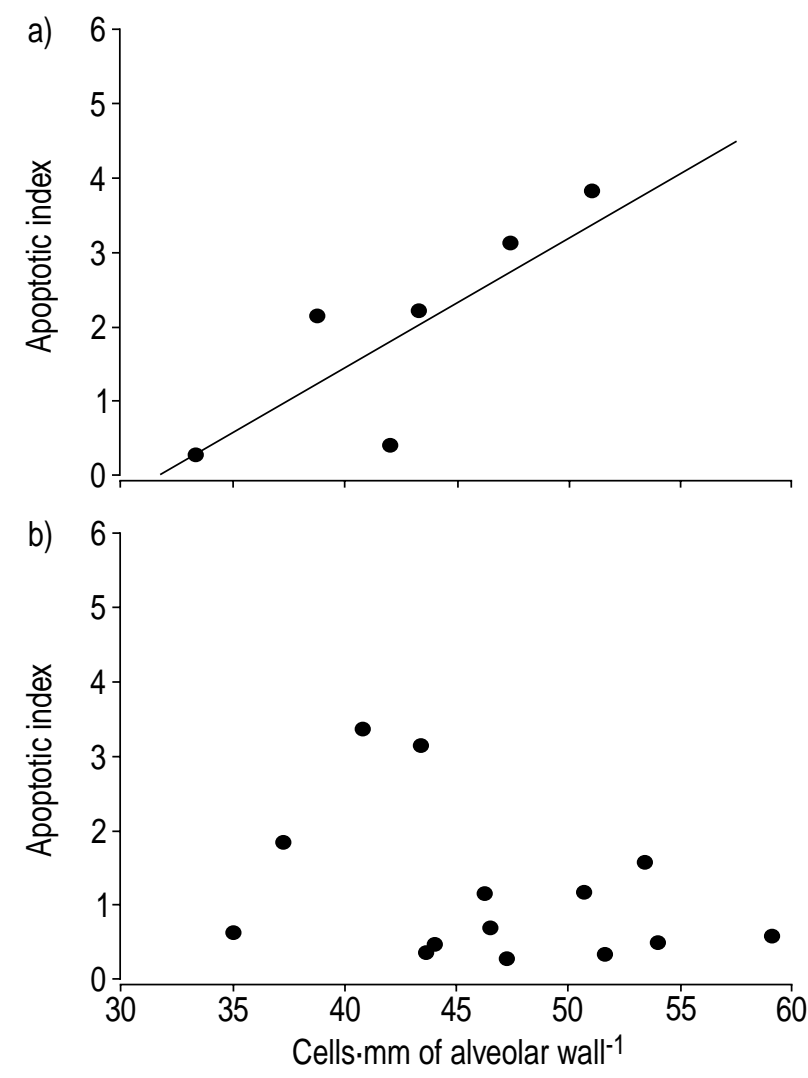

Fig. 5. - Relationship between the total cells $\cdot \mathrm{mm}$ of alveolar wall ${ }^{-1}$ and the apoptotic index in: a) nonsmokers $(r=0.829, p<0.05)$ and in b) smokers ( $r=-0.29$, NS).

without emphysema had a similar pattern to nonsmokers with a trend towards more CD $8+$ and $\gamma \delta$ T-cells. However, when emphysema developed, the CD3 + T-cells outnumbered the neutrophils and CD $8+$ T-cell numbers were significantly larger than in nonsmokers and smokers without emphysema. The presence of $\gamma \delta$ lymphocytes in the lung of smokers has not been previously reported. These T-cells are mainly

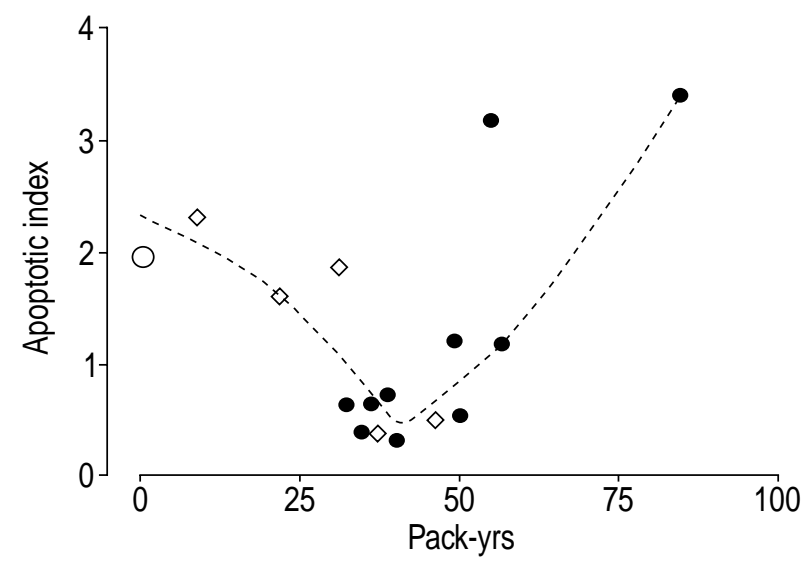

Fig. 6.-Relationship between the pack-yrs of smoking and the apoptotic index in $\bigcirc$ : nonsmokers; $\diamond$ : smokers with no emphysema; : smokers with emphysema. Lowess smoothing fit and defining a bilinear relationship with an $\mathrm{R}^{2}: 0.3613, \mathrm{p}=0.009$. 
found in the epithelial surfaces of the gut and in small numbers in the lung, but their function is not yet clear. A working hypothesis for the function of the $\gamma \delta$ $\mathrm{T}$-cells is that they may recognize antigens at boundaries between the host and external environment initiating immune responses to microbial or other antigens before recruitment of specific $\alpha \beta$ T-cells [23-25].

The different inflammatory pattern found in smokers, with and without emphysema, could be explained by either differences in susceptibility or to a dose effect of cigarette smoking. Therefore, the dose effect of smoking in the development of the inflammatory reaction was investigated. The present findings suggest that a certain number of years of smoking was necessary before a T-lymphocyte inflammatory reaction, in which all $\alpha \beta$ T-cells seemed to participate, became apparent (figs. 3 and 4), suggesting that there was a dose (packs $\cdot \mathrm{yr}^{-1}$ ) threshold for the inflammation to occur before emphysema became evident. Furthermore, as has been shown before, once lymphocytic inflammation appears the number of $(\mathrm{CD} 3+) \mathrm{T}$-cells in the alveolar wall is correlated with the severity of emphysema in smokers [9], suggesting a cause and effect relationship.

The present findings in the lung parenchyma are similar to those reported by SAETTA et al. [11] in the small airways of smokers, who found that the only difference between smokers with and without COPD, was an increased number of CD8 + T-cells in smokers with COPD. Similar results were reported by O'Shaughnessy et al. [10] in the large airways of smokers. Thus, only smokers who develop COPD have increased numbers of CD8 + T-cells in airways and lung parenchyma, underscoring the role of these cells in the pathogenesis of the disease.

Further support of the role of CD $8+\mathrm{T}$-cells in the production of lung destruction can be found in a recent report by DIAz et al. [26] showing that patients infected with human immunodeficiency virus (HIV) and high numbers of CD8 + T-cells in alveolar lavage had an accelerated onset of emphysema induced by smoking.

The role of T-lymphocytes in causing a particular immunological disease is suspected largely because of the demonstration of $\mathrm{T}$-cells in the diseased organ [27]. The functional activities of both $\mathrm{CD} 4+$ and CD8 + T-cells are initiated by the binding of specific antigen presented in association with the major histocompatibility complex (MHC) on the target cell to $\mathrm{T}$-cell antigen receptors. Once activated, T-cells migrate into the peripheral tissue, the lung in this case, which is the site of antigen entry and persistence [27-29]. Thus, the data invites speculation that after years of persistent neutrophilic and alveolar macrophage inflammation secondary to smoke, antigenic substances are being produced or released in the lung eventually leading to the activation, recruitment and accumulation of T-cells in some smokers. The ability of the CD8 + T-cells to produce lung injury has been recently described by EnELow et al. [29]. They conclusively demonstrated that recognition of a lung "autoantigen" by CD $8+$ T-cells is sufficient to produce lung injury in the absence of a stimulus such as viral infection, and that lung injury was mediated or amplified by inflammatory cells that are not antigen specific, like monocytes or macrophages.

The number of CD4+ T-cells in the lungs of smokers increased significantly after $\sim 30 \mathrm{yrs}$ of smoking as did the CD8 $+\mathrm{T}$-cells, suggesting that the CD4 + T-cell might be playing a role in the inflammatory process. CD $4+\mathrm{T}$-cell help is required for the priming of CD8 + cytotoxic T-cell responses for maintaining their memory, and for ensuring its survival, suggesting that even low numbers of CD4+ T-cells could be essential for the development of the CD8 + T-cell inflammatory infiltrate found in smokers [30].

The increase in the numbers of CD $8+\mathrm{T}$-cells seen in smokers with COPD suggests that these cells are activated. Most CD8 + T-cells are precytolytic and become cytolytic when they recognize Class I MHC associated peptides on professional antigen-presenting cells [25, 27]. Because apoptosis is one of the important end results of the effector function of cytolytic CD8 + T-cells, along with target cells necrosis and the promotion of nonspecific cellular inflammatory responses [27, 29], the presence of apoptosis in emphysema was investigated as indirect evidence of cytolysis by CD $8+$ T-cells. Only a small number of cells in all lungs showed apoptosis. However, the visualization of small percentages of apoptotic cells is biologically significant, since apoptotic cells are rapidly cleared by macrophages and dendritic cells [31]. Therefore, in a chronic slow progressing disease like pulmonary emphysema, a small number of apoptotic cells might represent a significant rate of tissue destruction.

Apoptosis was evident in nonsmoking lungs, a finding that contradicts a previous report [32] that did not find apoptosis in normal or cigarette-exposed human lungs. The apoptotic index in nonsmokers tended to be higher than in smokers with emphysema and was significantly related to the number of total cells $\cdot \mathrm{mm}$ alveolar wall ${ }^{-1}$ in nonsmokers $(r=0.829$; $\mathrm{p}<0.05$ ). Figure 5 shows that there was a large variation in the total number of cells in the alveolar wall of nonsmokers, and since the number of structural cells in the lung (alveolar type I \& II and endothelial cells) is fairly constant [33], the variability in the number of cells in nonsmokers is probably accounted for by different numbers of inflammatory cells, and apoptosis could represent homeostatic turnover of nonactivated inflammatory cells. In contrast, (fig. 5) in smokers with or without emphysema, no correlation was found between the total number of inflammatory cells and apoptosis $(r=-0.29$; Ns) suggesting that different cells are undergoing apoptosis in nonsmokers and smokers. In a recent report, KASAHARA et al. [34] also reported that apoptosis was present in smokers' lungs, but nonsmokers could have as high a number of apoptotic cells as smokers. Further investigations are needed to better clarify this complex phenomenon in smokers' and nonsmokers' lungs.

Apoptosis in smokers followed a bilinear trend when related to the smoking dose. In smokers without emphysema, the apoptosis index decreased from nonsmokers values, as smoking dose increased 
(fig. 6), possibly indicating the development of resistance to apoptosis due to the activation of inflammatory cells by smoking [35]. Neutrophils seem to become resistant to apoptosis in the presence of interleukin-8, a cytokine abundantly present in smokers' lungs [36]. Similarly, the apoptosis of T-cells changes with the state of activation of these cells. Naive T-cells die of apoptosis out of "neglect" [27], but in the initial stages of activation, T-cells become resistant to apoptosis in order to maintain immunological response [35]. In favour of this possibility is the behaviour of the Fas Index that normally increases upon antigen stimulation preparing the T-cells for potential apoptosis as a way to control autoimmunity $[35,37]$. In smokers, the significant correlation between the CD3 + numbers and the Fas index might indicate that these cells were being activated [27, 35].

In smokers with emphysema, apoptosis and CD8+ T-cells increased as the amount smoked increased, suggesting that the control of the immunological reaction was not successful ( $\mathrm{T}$-cells were not being eliminated), lymphocytes, mainly CD $8+$, proliferated and the number of cells undergoing apoptosis increased. Which cells were undergoing apoptosis were not identified; however, several recent reports [34, 38, 39] have identified an increased number of structural cells undergoing apoptosis in emphysematous lungs, supporting the idea that CD $8+\mathrm{T}$-cells are inducing apoptosis of structural cells in emphysematous lungs. The significant correlation between the number of CD8 + T-cells and apoptosis in active smokers would be in favour of this possibility. The identification of $\mathrm{CD} 8+\mathrm{T}$-cells expressing perforin and Fas Ligand in the lungs would add strength to this hypothesis [25].

The CD8 + T-cell inflammation in emphysematous lungs, the previous work describing a significant correlation between the number of T-cells in the alveolar wall and the extent of emphysema and the abundant literature describing the CD8 + T-cell infiltration of the airways of smokers with COPD, underscores the potential role of $\mathrm{T}$-cells in the pathogenesis of COPD. However, the possible role of T-cells in the pathogenesis of lung disease in smokers should not exclude a role for the neutrophils and macrophages traditionally associated with the pathogenesis of COPD. Moreover, participation of these cells is probably essential. In the authors' view, the following speculative explanation would link neutrophils, macrophages and lymphocytes in the pathogenesis of COPD. The authors hypothesize that smoking would promote an initial neutrophilic and macrophage inflammation and that by diverse mechanisms (proteases, oxidation, etc.) could damage lung cells and degrade interstitium (elastin, collagen, proteoglyeans, etc.). Lung injury may lead to structural alterations in self-antigens that create partially cross-reactive neo-antigens, and to the release of anatomically sequestered antigens [27, 29, 40] that could be recognized by autoreactive T-cells inducing their activation and proliferation. Through their effector functions, activated CD8 + and possible CD $4+$ T-cells could damage the lung by promoting further cellular inflammation (macrophages and neutrophils) [27, 29]; direct killing of target cells by perforin induced necrosis or perforin or Fas-Fas induced apoptosis [25, 40], and eventually producing the tissue destruction and remodelling seen in COPD.

If T-cells, alone or together with other inflammatory cells, are responsible for the lung injury and progression of chronic obstructive pulmonary disease, it would be as a response to an antigenic stimulus originating in the lung and induced by cigarette smoking. If that were the case, chronic obstructive pulmonary disease could be considered an autoimmune disease triggered by smoking.

Acknowledgements. The authors are indebted to J. Hogg and P. Pare for providing some of the cases, to $\mathrm{K}$. Whittaker for technical assistance and to C. Di Iorio for secretarial help.

\section{References}

1. Janus ED, Phillips NT, Carrell RW. Smoking lung function, and $\alpha_{1}$-antitrypsin deficiency. Lancet $1985 ; 1$ : $152-154$.

2. Black LF, Kueppers F. Alpha ${ }_{1}$-antitrypsin deficiency in non-smokers. Am Rev Respir Dis 1978; 117: 421428.

3. Gadek JE, Fells GA, Crystal RG. Cigarette smoking induces functional antiprotease deficiency in the lower respiratory tract of humans. Science 1979; 206: 13151316.

4. Hunninghake GW, Crystal RG. Cigarette smoking and lung destruction. Accumulation of neutrophils in the lungs of cigarette smokers. Am Rev Respir Dis 1983; 128: 833-838.

5. Martin TR, Ganesh R, Maunder RJ, Springmeyer SC. The effects of chronic bronchitis and chronic airflow obstruction on lung cell populations recovered by bronchoalveolar lavage. Am Rev Respir Dis 1985; 135: 254-260.

6. Hunninghake GW, Gadek JE, Kawanami O, Ferrans VJ, Crystal RG. Inflammatory and immune processes in the human lung in health and disease evaluation by bronchoalveolar lavage. Am J Pathol 1979; 97: 149206.

7. Anderson AE, Foraker AG. Pathogenic implications of alveolitis in pulmonary emphysema. Arch Pathol Lab Med 1961; 72: 44-58.

8. Eidelman D, Saetta MP, Ghezzo H, et al. Cellularity of the alveolar walls in smokers and its relation to lung destruction. Functional implications. Am Rev Respir Dis 1990; 141: 1547-1552.

9. Finkelstein R, Fraser RS, Ghezzo H, Cosio MG. Alveolar inflammation and its relation to emphysema in smokers. Am J Respir Crit Care Med 1995; 152: 1666-1672.

10. O'Shaughnessy TC, Ansari TW, Barnes NC, Jeffery PK. Inflammation in bronchial biopsies of subjects with chronic bronchitis: inverse relationship of CD8+ T-lymphocytes with FEV1. Am J Respir Crit Care Med 1996; 155: 852-857.

11. Saetta M, Di Stefano A, Turato G, et al. CD8+ 
T-lymphocytes in the peripheral airways of smokers with chronic pulmonary disease. Am J Respir Crit Care Med 1998; 157: 822-826.

12. Lams BE, Sousa AR, Rees PJ, Lee TH. Immunopathology of the small airway submucosa in smokers with and without chronic obstruction pulmonary disease. Am J Respir Crit Care Med 1998; 158: 15181523.

13. Ferris BG. Epidemiology standardisation project. III. Recommended standardized procedures for pulmonary function testing. Am Rev Respir Dis 1978; 118: 55-88.

14. Morris JF, Kolski WA, Johnson LC. Spirometric standards for healthy non-smoking adults. Am Rev Respir Dis 1971; 103: 57-63.

15. Goldman HI, Becklake MR. Respiratory function tests. Normal values at median altitudes and the prediction of normal results. Am Rev Tuberc 1959; 79: 457-467.

16. Kim WD, Eidelman DH, Izquierdo JL, Ghezzo H, Saetta MP, Cosio MG. Centrilobular and panlobular emphysema in smokers. Am Rev Respir Dis 1991; 144: 1385-1390.

17. Frew AJ, Kay AB. The relationship between infiltrating CD4 lymphocytes, activated eosinophils and the magnitude of the allergen-induced late phase cutaneous reaction in man. $J$ Immunol 1988; 141: 4158 4164.

18. Saetta M, Shiner RJ, Angus GE, et al. Destructive index: a measurement of lung parenchymal destruction in smokers. Am Rev Respir Dis 1985; 131: 764 769.

19. Cleveland WS. Robust locally weighted regression and smoothing scatter plots. J Am Stat Assoc 1979; 74: 829-836.

20. Finkelstein R, Ma HD, Ghezzo H, Whittaker K, Fraser RS, Cosio MG. Morphometry of small airways in smokers and its relationship to emphysema type and hyperresponsiveness. Am J Respir Crit Care Med 1995; 152: 267-276.

21. DiStefano A, Turato G, Maestrelli P, et al. Airflow limitation in chronic bronchitis is associated with $\mathrm{T}$ lymphocyte and macrophage infiltration of the bronchial mucosa. Am J Respir Crit Care Med 1996; 153 : 629-632.

22. Costabel U, Bross $\mathrm{KJ}$, Reuter $\mathrm{CH}$, Ruhle $\mathrm{KH}$, Matthys H. Alterations in immunoregulatory T-cell subsets in cigarette smokers. A phenotypic analysis of bronchoalveolar and blood lymphocytes. Chest 1986; 90: 39-44.

23. Fajac I, Tazi A, Hance AJ, et al. Lymphocytes infiltrating normal human lung and lung carcinomas rarely express $\gamma \delta$ T-cell antigen receptors. Clin Exp Immunol 1991; 87: 127-131.

24. Groh V, Steinle A, Bauer S, Spies T. Recognition of stress-induced MHC molecules by intestinal epithelial $\gamma \delta$ T-cells. Science 1998; 279: 1737-1740.

25. Kägi D, Lederman B, Börki K, Zinkernagel RM, Heugartner H. Molecular mechanisms of lymphocyte mediated cytotoxicity and their role in immunological protection and pathogenesis in vivo. Ann Rev Immunol 1996; 14: 207-232.

26. Diaz PT, King MA, Pacht ER, et al. Increased susceptibility to pulmonary emphysema among HIVseropositive smokers. Ann Intern Med 2000; 132: 369372.

27. Abbas AK, Lichtman AH, Pober JS. Cellular and molecular immunology. 4th edition. Saunders Text and Review series, Philadelphia, W.B. Saunders Co., 2000.

28. Zinkarnagel RM, Ehl S, Aichele P, Oehen S, Kundig $T$, Hengartner $H$. Antigen localisation regulates immune responses in a dose and time-dependent fashion: a geographical view of immune reactivity. Immunol Rev 1997; 156: 199-209.

29. Enelow RI, Mohammed AZ, Stoler MH, et al. Structural and functional consequences of alveolar cell recognition by $\mathrm{CD} 8(+)$ t-lymphocytes in experimental lung disease. J Clin Invest 1998; 102: 16531661.

30. Frasca L, Piazza C, Piccolella E. CD4 \& T-cells orchestrate both amplification and deletion of CD8+ T-cells. Crit Rev Immunol 1998; 18: 569-594.

31. Bursch W, Paffe S, Putz B, Barthel G, ShulteHermann R. Determination of the length of Histological stages of apoptosis in normal liver and in altered hepatic foci of rats. Carcinogenesis 1990; 11: 847-853.

32. Kuwano K, Kunitake R, Kawasaki M, et al. P21 Waf1/ Cip1/Sdi1 and p53 expression in association with DNA strand breaks in idiopathic pulmonary fibrosis. $\mathrm{Am}$ J Respir Crit Care Med 1996; 154: 477-483.

33. Crapo JD, Barry BE, Gehr P, Bachofen M, Weibel ER. Cell number and cell characteristics of the normal human lung. Am Rev Respir Dis 1982; 125: 332-337.

34. Kasahara Y, Tuder RM, Cool CD, Lynch DA, Flores SC, Voelkel NF. Endothelial cell death and decreased expression of vascular endothelial growth factor and vascular endothelial growth factor receptor in emphysema. Am J Respir Crit Care Med 2000; 163: 737-744.

35. Lenardo M, Chan KM, Hornung F, et al. Mature T-lymphocyte apoptosis. Immune regulation in a dynamic and unpredictable antigenic environment. Ann Rev Immunol 1999; 17: 221-253.

36. Glynn P, Henney E, Hall IP. Inhibition of spontaneous apoptosis of human neutrophils by interleukin8. Am J Respir Crit Care Med 2000; 161: A338.

37. Nagata S, Golstein P. The Fas death factor. Science 1995; 267: 1449-1456.

38. D'Armiento J, Franke T, Imai K. Apoptosis in human emphysema lungs. Implications for novel therapeutic strategies. Am J Respir Crit Care Med 2000; 161: A812.

39. Yokohori N, Aoshiba K, Yasui S, Nagai A. Epithelial apoptosis in a murine model of elastase-induced pulmonary emphysema. Am J Respir Crit Care Med 2000; 161: A817.

40. Chau-Ching L, Young LHY, Young JDE. Lymphocytemediated cytolysis and disease. N Engl J Med 1996; 335: 1651-1659. 